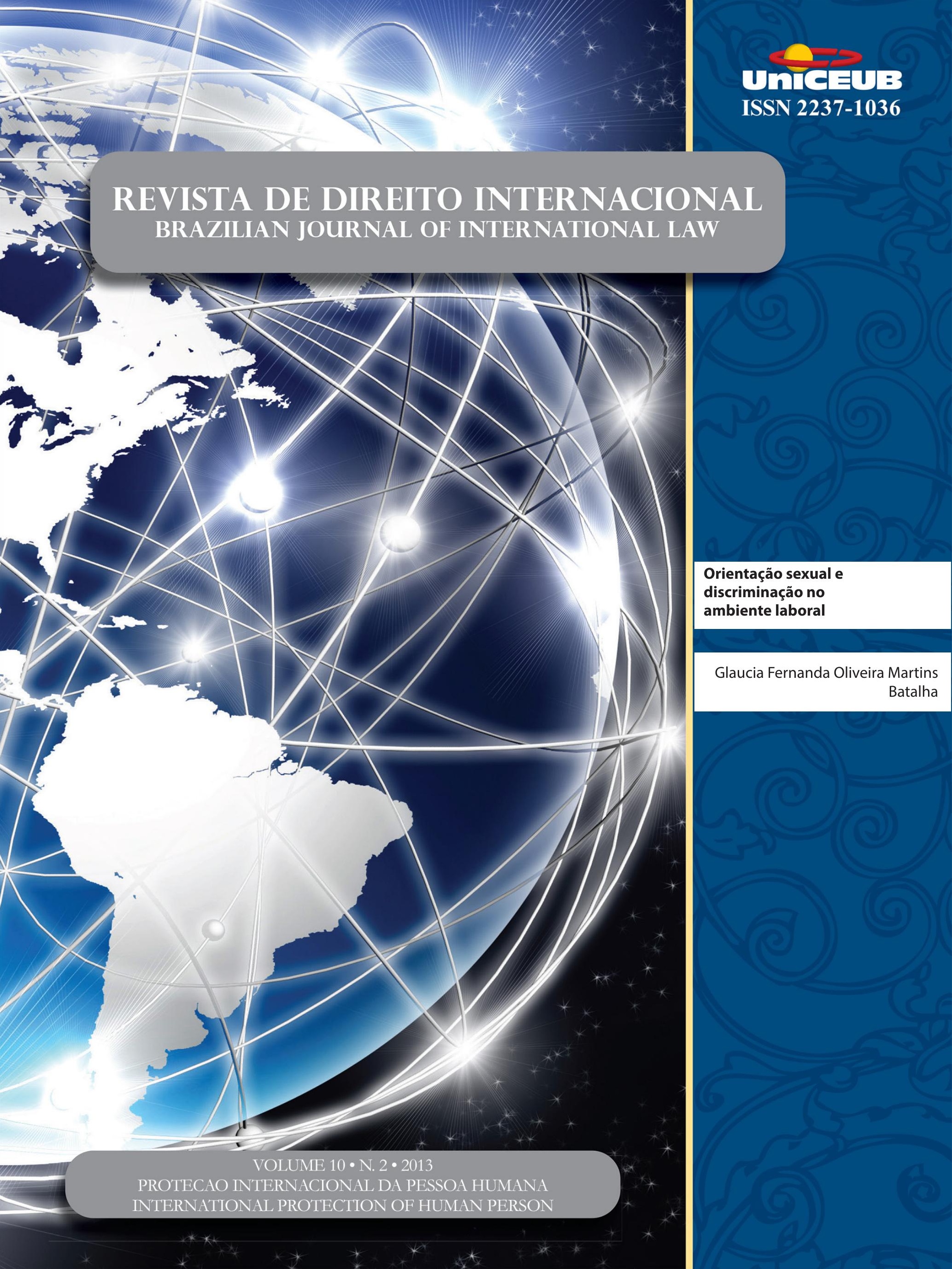




\section{Artigo Especial}

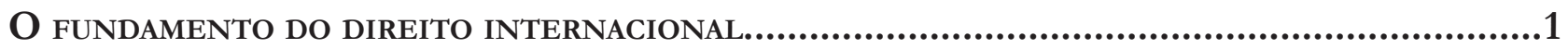
Alfred Verdross

\section{Proteção Internacional dos Direitos Humanos}

INDIGENOUS RIGHTS MOVEMENT: IS THE SAME NEEDED TO PREVENT CONTINUED HUMAN RIGHTS VIOLATIONS OF THE MENTALLY ILL

Liesel LeCates

O Discurso DAS DROGAS CONSTRUído PELO DIREITO INTERNACIONAL

Camila Soares Lippi

O ESTADO DEMOCRÁTICO DE DIREITO LAICO E A "NEUTRALIDADE" ANTE A INTOLERÂNCIA RELIGIOSA

Antonio Baptista Gonçalves

UM DiREITO SEM ESTADO? DiREITOS humanos E A FORMAÇÃo DE UM NOVO QUADRo NORMATIVO GLOBAL .87

Anderson Vichinkeski Teixeira e Rafael Köche

\section{Direito Humanitário}

The U.N. Standard Minimum Rules for the Treatment of Prisoners and North Korea: How North Korea is Violating these Rules with its Operation of the Yodok Concentration CAMP.

Tom Theodore Papain

U.S. Institutionalized Torture with Impunity: Examining Rape and Sexual Abuse in Custody Through the ICTY JurisprudenCE. 126 Allison Rogne 
Abduction, Torture, Interrogation: An Argument Against Extraordinary RendiTION

Kaitlyn E. Tucker

United States and European Union approaches to the death penalty: America SHOULD CONSIDER A NEW PERSPECTIVE 155 Katie R Hill

Tudo DE NOVO NO FRONT: MONUSCO, UMA NOVA ERA NAS PEACEKEEPING OPERATIONS? .169 Priscila Fett

A ADMINISTRAÇÃo DE TERRITÓRIOS OCUPADOS: INDETERMINAÇÃO DAS NORMAS DE DIREITO INTERNACIONAL HUMANITÁRIO?. 184 João Henrique Ribeiro Roriz, Fabia Fernandes Carvalho Veçoso e Lucas da Silva Tasquetto

THE (IN)APPLICABILITY OF THE STATUTE OF REFUGEES TO ENVIRONMENTALLY DISPLACED PERSONS 197 Maria Cláudia da Silva Antunes de Souza e Lucas de Melo Prado

\section{Sistema Interamericano de Direitos Humanos}

A contribuição da Comissão Interamericana de Direitos Humanos para o acesso À jus-

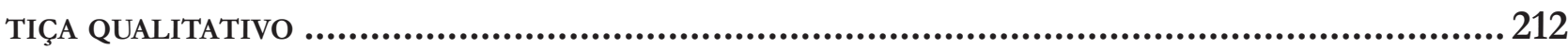
Márcio Antônio de Oliveira Filho, Ana Caroline Portes de Oliveira, Jéssica Galvão Chaves e Warlen Soares Teodoro

A executividade das sentenças da Corte Interamericana de Direitos Humanos no

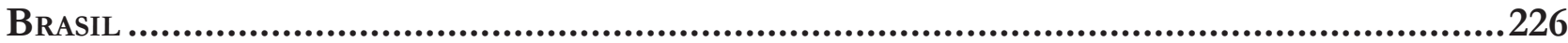

Augusto César Leite de Resende

A efetividade do ativismo jurídico transnacional no Sistema Interamericano de DiREITOS HuMANOS: UMA ANÁLISE A PARTIR DE CASOS CONTRA O BRASIL .................................238 Renata Mantovani de Lima e Lucélia de Sena Alves

O Processo e o Direito Coletivo no Sistema Interamericano de Direitos Humanos: UMA ANÁLISE COM BASE NA JURISPRUDÊNCIA INTERNACIONAL ...........................................250 Laercio Dias Franco Neto e Dafne Fernandez de Bastos 
CORTE INTERAMERICANA DE DIREITOS HUMANOS: OPINIÃo CONSULTIVA 4/84 - A MARGEM DE

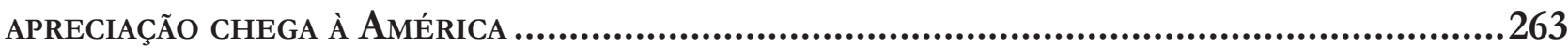

Paloma Morais Corrêa

A "PLENA" LIBERDADE DE EXPRESSÃo E OS DIREITOS HUMANOS: ANÁLISE DA JURISPRUDÊNCIA DA Corte InTeramericana de Direitos Humanos e o Julgamento da ADPF 130 281 Natália Paes Leme Machado

A proteção do meio ambiente no Sistema Interamericano de Direitos Humanos a parTIR DO DIREITO À EDUCAÇÃO.

Augusto César Leite de Resende

Parameters and procedures of the Inter-American System of Human Rights in CHILDREN'S RIGHTS VIOLATION LAWSUITS

Maria Guiomar da Cunha Frota e Pedro Alves Barbosa Neto

Poverty as a Violation of Human Rights: THE CASE OF STREET CHILDREN IN GUATEMALA AND BRAZIL

Paloma Morais Correa

\section{Proteção Internacional dos Direitos Humanos e o Direito Brasileiro}

A LEI N. 11.340/06 E SUAS REPERCuSSõES No CONTRATO INDIVIDUAL DE TRABALHo. Humberto Lima de Lucena Filho e Waldeny Pereira Filho

ORIENTAÇÃo SEXUAL E DISCRIMINAÇão NO AMBIENTE LABORAL

Glaucia Fernanda Oliveira Martins Batalha

NORMAS EDITORIAIS 


\title{
Orientação sexual e discriminação no ambiente laboral
}

\author{
Glaucia Fernanda Oliveira Martins Batalha**
}

\section{Resumo}

Apesar das grandes transformações no âmbito da economia e de todos os avanços na tecnologia, o Brasil ainda continua a ser um país de contrastes e que possui uma cultura social e política de tradição autoritária e conservadora. É o que se observa diante do enfrentamento da problemática da discriminação em torno das minorias sexuais. Ainda que os direitos fundamentais estejam explícitos na Carta Magna Nacional, grupos vulneráveis como estes continuam à margem da sociedade, não são facilmente visualizados no Estado Nacional, Estado este efetivamente laico e democrático, e que garante materialmente tais direitos. Garantir a homossexuais o direito de expressar sua orientação sexual em qualquer situação, mormente no ambiente de trabalho, nada mais é do que aplicar os princípios fundamentais presentes na Carta Magna, bem como tornar efetivos os enunciados previstos na Declaração Universal dos Direitos Humanos. Neste trabalho, optou-se por limitar o objeto de estudo à questão da discriminação por orientação sexual nas relações de trabalho, restringindo ainda esta temática, exclusivamente sobre a discriminação, envolvendo apenas homossexuais, ou seja, gays e lésbicas.

Palavras-chave: Discriminação. Homossexuais. Orientação Sexual. Relações de trabalho. Grupos vulneráveis.

\section{Abstract}

Notwithstanding the major transformations in world economy and all advances in technology, Brazil is still a country marked by contrasts, bearing an authoritarian and conservative tradition. This can be clearly observed in the struggle to reduce discrimination against sexual minorities. Even with the fundamental rights written explicitly in the National Constitution, those vulnerable groups still find themselves marginalised, for it is hardly possible to visualize in the Brazilian State, true laicism and democratic order able to promptly guarantee those rights. Ensuring that homosexuals have the right to express their sexual orientation in any given situation, mainly in the work environment, is nothing more than to abide by the fundamental principles written in the constitution as well as following the principles declared in the Universal Declaration of Human Rights. The present work will narrow its scope to the study of the discrimination against sexual orientation in the work environment, further restricting its analysis on the discrimination against homosexuals only, namely, gays and lesbians.

Keywords: Discrimination. Homosexuals. Sexual orientation. Work relations. Vulnerable groups. 


\section{INTRODUÇÃO}

No âmbito do mercado de trabalho, o preconceito é uma realidade manifesta, uma vez que a homossexualidade não é vista com bons olhos pelas empresas. O ambiente de trabalho, sem dúvida, é uma área ainda eivada de preconceitos, com posicionamentos conservadores bastante arraigados, sobretudo no que se refere à orientação sexual e à identidade de gênero.

Quem nunca ouviu falar que um amigo teve uma promoção negada por ser assumidamente gay? Ou de uma amiga que não foi admitida em uma empresa por ter feições e trejeitos masculinizados? Que um colega de trabalho é motivo de "chacota" e sente-se discriminado pela maioria dos funcionários por ser homossexual? Quem, em algum momento da vida, não ficou frente a frente com a marginalização que sofrem os homossexuais devido à diferença de orientação sexual?

Essas não são suposições imaginárias e/ou situações fictícias, pelo contrário, são dados e situações reais vivenciadas frequentemente. Embora poucos homossexuais tenham coragem de denunciar e sejam quase inexistentes os dados nacionais que dimensionem o tamanho do preconceito, é sabido que a discriminação existe e tende a aumentar se nada for feito.

O tema deste trabalho surgiu em razão da homossexualidade representar, para os tomadores de serviços, um impasse na contratação e na manutenção de homossexuais no emprego. Isso torna a revelação de sua sexualidade um obstáculo na caminhada em busca da realização econômica, social, psicológica e na conquista de uma existência digna. Essa realidade deve ser mudada.

Nesses termos, o presente trabalho visa analisar a questão da discriminação de homossexuais no mercado de trabalho, pois a inserção formal nos textos constitucionais do princípio da igualdade, da dignidade e da liberdade, bem como a proibição de condutas discriminatórias não bastam para que homossexuais sejam preteridos em um emprego.

O objetivo deste trabalho é tratar do tema discriminação por orientação sexual ${ }^{1}$ no mercado de trabalho.

1 Tem-se por escopo demonstrar que a discriminação por orientação sexual, motivada pelo preconceito de aceitar tal diferença e pela falta de observância ao princípio constitucional de que todos são iguais perante a lei, relega à marginalidade pessoas homossexuais, pois elas só podem ser aceitas nas relações sociais e trabalhistas se esconderem sua própria sexualidade.

\section{DISCRIMINAÇÃO POR ORIENTAÇÃO SEXUAL: UMA REALIDADE}

Nos dias de hoje, apesar de o legislador constituinte assegurar a igualdade e trazer no bojo da Constituição a proibição de qualquer tipo de discriminação, trabalhadores homossexuais ${ }^{2}$ deixam de ser contratados, são despedidos ou têm sua carreira profissional afetada por causa de sua orientação sexual.

Acredita-se que a discriminação operada contra homossexuais no mercado de trabalho, deve-se à arraigada mentalidade heterossexista ${ }^{3}$ e homofóbica ${ }^{4}$ dos tomadores de serviços, uma vez que não há dados que comprovem que a homossexualidade tenha influência na produtividade e na capacidade profissional.

A homossexualidade, por si só, é vista, por muitos, como um misto de pecado-doença-crime, despertando rejeições de intensidades variadas em diferenciados segmentos sociais; o que faz dos homossexuais um dos agrupamentos mais atingidos pelas complexas lógicas de intolerância, preconceito ${ }^{5}$ e discriminação. ${ }^{6}$

A discriminação no curso da relação de emprego é mais voraz quando diz respeito a homossexuais. Os atentados contra a dignidade da pessoa humana são profundos no caso da questão homossexual. O estereótipo ${ }^{7}$ de perversão ou de doença isola homossexuais da

2 O homossexual é a pessoa que se sente atraída, sexual, afetiva e emocionalmente por pessoas do mesmo sexo.

3 O heterossexismo é um termo mais abrangente do que a homofobia, sendo que esta é resultante do heterossexismo. O que diferencia o heterossexismo da homofobia é que aquele negligencia ou omite a homossexualidade, enquanto que a homofobia nada mais é do que um medo irracional ou ódio em relação a gays e lésbicas.

4 Trata-se a homofobia, de uma opressão intencional e premeditada que inclui preconceito, discriminação, desprezo, abuso verbal, atos de violência, ódio generalizado, entres outras espécies de represália dispensadas ao comportamento homossexual.

Ademais, ao mesmo tempo em que tais sentimentos causam medo e repugnância ao dito comportamento, também propiciam uma vida eivada de privações, renúncias e sacrifícios, por receio de ser homossexual, ou de que os outros pensem que se é.

5 O preconceito trata-se de uma indisposição, um julgamento prévio, negativo.

6 MELLO, Luiz. Outras famílias: a construção social da conjugalidade homossexual no Brasil. Cadernos Pagu no 24 Campinas Jan./June 2005. Disponível em: <http://www.scielo.br/scielo. php? script $=$ sci_arttext\&pid $=$ S0104-83332005000100010 $>$. Acesso: 20 de fev. de 2010.

7 É utilizado para designar características negativas, comportamentos ou rótulos depreciativos, inferir imperfeições que marcam o indivíduo causando vergonha e desaprovação, levando à discriminação social. 
sociedade, obrigando-os, muitas vezes, ao silêncio e ao constrangimento diante de pilhérias que são comuns em nossa sociedade. ${ }^{8}$

A relação empregatícia é um campo fértil para a propagação de práticas discriminatórias do ponto de vista geral. A discriminação em razão da homossexualidade é tão presente no mercado de trabalho, que pode vir a restringir a área de atuação profissional do homossexual que expõe e/ou declara sua orientação sexual. É o que aponta Álvaro Ricardo de Souza Cruz, ao tratar da discriminação ao homossexual no trabalho: "Parece-nos que a sociedade ocidental admite a presença do homossexual em algumas áreas e outras não. Claramente é assim no mundo da "alta costura" de um lado e, de outro, no campo militar."

No âmbito do esporte, o futebol tem sido uma atividade profissional "proibida" para esse grupo. Em 2007, os meios de comunicação trouxeram à tona um dos principais tabus das "arenas da bola", qual seja a possibilidade de o jogador de futebol assumir sua orientação sexual. É o que se verifica na reportagem intitulada de "Ele não usa sapatilhas, mas chuteiras", de "O Liberal":

Quem convive de perto com o mundo do futebol sabe: assumir que é gay pode fazer ruir a carreira, acabar as boas relações com a torcida, imprensa e companheiros. Por isso, o volante Richarlyson agiu rápido quando, num programa de TV, o diretor administrativo do Palmeiras, José Cyrillo Júnior, insinuou que o jogador do São Paulo era gay. Richarlyson, 24 anos, decidiu entrar com uma queixa-crime contra Cyrillo. E o juiz Manoel Maximiliano Junqueira Filho recusou a queixa alegando que futebol não é lugar de gays. ${ }^{10}$

A sentença do Juiz de Direito Manoel Maximiliano, além de criticar a presença da homossexualidade nos gramados brasileiros, também evidenciou discriminação ilegítima contra esse grupo vulnerável. Observe-se a reportagem "Telma, eu não sou gay", de "O Liberal":

São numerosos e rumorosos os casos de homossexualidade no futebol, inclusive na Seleção Brasileira, mas duas semanas atrás uma sentença judicial causou espanto: o juiz Manoel Maximiliano se recusou a apreciar um pedido de liminar porque o requerente, o volante Richarlyson, do São Paulo, seria homossexual. Para o juiz, "era

8 CRUZ, Álvaro Ricardo de Souza. O direito à diferença: as ações afirmativas como mecanismo de inclusão social de mulheres, negros, homossexuais e pessoas portadoras de deficiência. Belo Horizonte: Del Rey, 2003. p. 114-115.

9 Opus cit. p.115.

10 COELHO, Edson. Ele não usa sapatilhas, mas chuteiras. Jornal O Liberal-Belém, 26.08.2007. melhor que abandonasse os gramados", escreveu na sentença, e mais; "futebol é jogo viril, varonil, não homossexual"; e ainda: "homossexualismo é um situação incomum do mundo moderno que precisa ser rebatida"; e, para abrilhantar a magistral sentença do magistrado: "Não poderia sonhar vivenciar um homossexual no futebol". ${ }^{11}$

Sylvia Maria Mendonça do Amaral, quando discorre sobre o "caso Richarlyson", deixa claro o preconceito e discriminação de que são alvo os homossexuais:

Não podemos negar, infelizmente, que a homofobia está presente em nosso país. Os atos homofóbicos partem de todos os lados, de todas as maneiras, de uma palavra vulgar a assassinatos. Mas o que podemos dizer quando a discriminação parte de um Juiz de Direito que está a serviço da Justiça?

Um caso de homofobia envolvendo o jogador do São Paulo Futebol Clube, Richarlyson, virou manchete dos principais veículos de comunicação do país. O juiz da 9a Vara Criminal de São Paulo, Manoel Maximiano Junqueira Filho, mandou arquivar o processo movido pelo jogador contra um dirigente do Palmeiras que, em um programa de televisão, insinuou que o atleta era homossexual. Em seu despacho, entre inúmeras declarações homofóbicas, o juiz afirmou que "não poderia jamais sonhar em vivenciar um homossexual jogando futebol".

O "caso Richarlyson" demonstra o grau de homofobia que assola nosso país. Mas o jogador tem demonstrado sua coragem e partiu para lutar pelos direitos constitucionalmente garantidos não só a ele como a todos nós, cidadãos, que são: honra, dignidade, igualdade e privacidade. Richarlyson poderia ter agido de três formas diferentes nesta situação: ter se recolhido e não levar a história adiante, agir por ele mesmo ou, e aí é que está o seu brilhantismo, lutar por todos nós.

Conhecedor das regras de civilidade, respeito e justiça, o jogador está agindo contra o preconceito e discriminação de um diretor de clube de futebol e de um Juiz de Direito, a quem recorreu para clamar por justiça. Ocorre que esse que deveria ser o seu defensor não só indeferiu seu pedido e o repeliu como proferiu sentença ainda mais preconceituosa e homofóbica do que as ofensas praticadas por seu primeiro agressor. ${ }^{12}$

Também é válido chamar a atenção para a polêmica decisão do prefeito de Campo Grande/MS, Nelson Trad. Filho, que afastou de uma escola pública duas

11 COELHO, Edson. Telma, eu não sou gay. Jornal O LiberalBelém, 26.08.2007.

12 AMARAL, Sylvia Maria Mendonça do. Caso Richarlyson e a homofobia. Revista Jurista, João Pessoa, a. III, n. 92, 19/09/2006. Disponível em: <http://www.juristas.com.br/mod_revistas. asp?ic $=2972>$. Acesso: 27 ago. 2007. 
professoras porque descobriu que elas mantinham uma relação homoafetiva. ${ }^{13}$ É o que foi veiculado em rede nacional:

Duas professoras de Campo Grande foram afastadas da escola pública onde trabalhavam porque se apaixonaram uma pela outra. Uma decisão polêmica e que, para muitos, tem nome: discriminação. ${ }^{14}$

Ainda sobre tal questão, vejamos:

O caso das duas professoras de Campo Grande, Carmem Silvia Geraldo (52 anos) e Noyr Rondora Marques (38), que foram demitidas da escola onde lecionavam, Escola Professora Onira Rosa dos Santos, ao que tudo indica por serem companheiras, continua rendendo notícia.

Corajosas, as professoras denunciaram o caso à imprensa (deram entrevista ao Fantástico) e decidiram exigir indenização da Prefeitura da cidade pelo ato discriminatório. ${ }^{15}$

Entretanto, não é só no universo do futebol ou no âmbito escolar que revelar a homossexualidade significa arruinar a carreira profissional. Infelizmente, a maioria dos empregadores é extremamente heterossexista, e, consequentemente, preconceituosa, de modo que existem diversos casos relatados por $\mathrm{ONG}^{\text {' }}{ }^{16}$ que lutam contra o preconceito no ambiente de trabalho, como bem se percebe em artigos que trazem à tona a discriminação tão presente nesse segmento da vida do homossexual:

Vários são os casos relatados por ONGs, Grupos de defesa das minorias ou Associações de defesa dos direitos dos homossexuais, de empresas que criam situações de extremo desconforto no profissional que expressa sua preferência sexual. Existem casos relatados pela ONG Nuances - Grupo pela livre Expressão Sexual - baseado no Estado do Rio

13 O direito de família pós-moderno, diante das profundas modificações sofridas ao longo do tempo, denomina a relação homossexual como "homoafetiva" porque o que a carrega é o afeto. Vide: DIAS, Maria Berenice. União homossexual: o preconceito e a justiça. 2.ed.Porto Alegre: Livraria do Advogado. 2001.

14 GLOBO, Rede. Professoras discriminadas. Disponível $\quad$ em: $<$ http://fantastico.globo.com/Jornalismo/Fantastico/0, AA1662347-4005-755999-0-18112007,00.html>. Acesso: 20 nov. 2007. 15 UM OUTRO OLHAR, REDE. Professoras discriminadas em Campo Grande. Disponível em: <http://www.umoutroolhar. com.br/em_movimento.htm\#Professoras_discriminadas_em_Campo_Grande>. Acesso: 25 nov. 2007.

16 Organizações não governamentais, associações independentes dos poderes políticos, que agem de maneira benevolente, principalmente no campo dos direitos humanos, no âmbito de uma ajuda de emergência ou duradoura em favor do desenvolvimento. Disponível em: <http://www.dhnet.org.br/direitos/sip/textos/glossario. html> Acesso: 20 nov. 2007.
Grande do Sul, em que empresas multinacionais tomam ciência da discriminação - e até incentivam - seus funcionários a discriminarem o colega. Por estes motivos vários processos judiciais foram iniciados pelas ONGs que trabalham em defesa dos direitos dos homossexuais, tendo acontecido até de juízes de primeira e segunda instância proferirem sentenças favoráveis aos discriminados sexualmente. Algumas ONGs conseguiram a ajuda valiosa do Ministério Público do Trabalho que em alguns casos apresenta denúncia contra as empresas que discriminam ou aceitam atos de discriminação por parte de seus funcionários contra colegas homossexuais.

Neste sentido, trabalho iniciado pela Coordenadoria Nacional de Promoção da Igualdade de Oportunidades e Eliminação da Discriminação no Trabalho - uma Divisão do Ministério Público do Trabalho - criada em 2002 para estabelecer ações efetivas nas diversas procuradorias regionais do trabalho - concluiu que o grande problema da discriminação hoje é a falta de provas, pois a legislação já ampara as pessoas que são discriminadas, desde que haja a denúncia, e o MPT age como aliado das pessoas discriminadas, inclusive sexualmente. ${ }^{17}$

Corrobora com tal assertiva o artigo da revista da ANAMATRA, ${ }^{18}$ atinente ao auxílio de ONG's na luta contra a discriminação:

Hoje, as ONGs são imprescindíveis no encaminhamento das denúncias, pois encorajam as pessoas a denunciarem e apresentam a elas o caminho para o reconhecimento dos seus direitos. Esse é o importante papel desempenhado pelo Núcleo de Lésbicas da ONG brasiliense Estruturação. O grupo se reúne semanalmente com mulheres e, nesses dias, algumas mulheres relatam momentos positivos e negativos vivenciados por elas, inclusive no trabalho. Um dos casos relatados é, por exemplo, o de uma mulher que foi alertada por seu chefe que nem fora do ambiente de trabalho ela poderia expor publicamente a relação que mantém, para não afetar a imagem da empresa.

Até a roupa, que pode sugerir a orientação sexual, é comentada por chefes, e pedidos atípicos, como a obrigatoriedade de usar brincos, são apresentados para desmotivar a profissional e estimular a sua demissão. "Como as decisões da Justiça variam, é um risco a pessoa entrar com a ação. Então, sugerimos esse caminho, mas trabalhamos o fortalecimento da autoestima e trocas de experiências para que ela busque outras alternativas de solução do problema", diz a coordenadora do núcleo de Lésbicas da Estruturação, Kelly Kotlinski. ${ }^{19}$

17 BLÁBLÁBLÁ, Jornal. O Mercado de trabalho. Disponível em: <http://jornalblablabla.blogspot.com/2007/05/o-mercadode-trabalho.html>. Acesso: 10 jun. 2007.

18 Associação Nacional dos Magistrados da Justiça do Trabalho.

19 ANAMATRA. Os iguais de forma diferente: quando a dis- 
Nesse compasso, apesar de todo o auxílio das ONGs do Ministério Público do Trabalho ${ }^{20}$, de algumas vozes de juristas e de uma pequena parcela da sociedade, a percepção lógica mostra que as práticas sexuais entre pessoas do mesmo sexo continuam sendo condenadas, repugnadas.

Não se pode admitir que, em pleno século XXI, o Estado Democrático de Direito concebido por uma Constituição Federal que traz em seu bojo direitos e garantias fundamentais - que versam acerca do direito à igualdade, da dignidade humana, da liberdade, da inviolabilidade da intimidade da vida privada, da cidadania e dos valores sociais do trabalho, e que traga, como um dos pilares de sustentação da ordem econômica nacional, a valorização do trabalho, com a finalidade de propiciar existência digna e distribuir justiça social, por meio da redução das desigualdades sociais - haja com negligência em torno da discriminação sofrida por homossexuais, quer seja no mercado de trabalho, quer seja em toda a sociedade pátria.

É por demais necessária a implementação de mecanismos que garantam a homossexuais a estabilidade no emprego e a proteção contra despedidas arbitrárias, pois a inserção formal nos textos constitucionais do princípio da igualdade, da dignidade e da liberdade, bem como a proibição de condutas discriminatórias não bastam para que homossexuais sejam preteridos em um emprego.

Dentre os mecanismos de proteção a homossexuais no mercado de trabalho, levam-se em conta os ensinamentos do Ronald Dworkin, pois se entende que as políticas de ações afirmativas são um grande trunfo para o reconhecimento da igualdade material e formal desses sujeitos marginalizados. ${ }^{21}$

Busca-se fazer referência a algumas normas de combate à discriminação e medidas de ações afirmativas voltadas para esse grupo vulnerável.

criminação no trabalho atinge os homossexuais. Disponível em: $<$ http://anamatra.org.br/publ/periodicos/rev_anamatra/rev_template_int.cfm?cod_mat $=230>$. Acesso: 17 ago. 2007.

20 O Ministério Público do Trabalho (MPT) é um dos ramos do Ministério Público da União, que também compreende o Ministério Público Federal, o Ministério Público Militar e o Ministério Público do Distrito Federal e Territórios. Tem como chefe o Procurador-Geral do Trabalho, eleito em lista tríplice e nomeado pelo Procurador-Geral da República. Compõem o MPT a ProcuradoriaGeral, com sede em Brasília/DF, 24 Procuradorias do Trabalho em municípios. Disponível em: < http://www.mpt.gov.br/ > Acesso: 20 nov. 2007.

21 DWORKIN, Ronald. A virtude soberana: teoria e prática da igualdade. São Paulo: Martins Fontes, 2005.

\section{Mecanismos e normas de combate À DISCRIMINAÇÃO POR ORIENTAÇÃO SEXUAL}

Objetiva-se neste ponto discorrer, ainda que brevemente, a respeito dos mecanismos e modelos de combate às práticas discriminatórias - mais especificamente a ação afirmativa - bem como tratar de normas que vedam as práticas discriminatórias referentes à orientação sexual na relação de emprego.

Quanto aos textos normativos que protegem contra a discriminação, é de se observar a existência de normas nacionais e internacionais que têm por intuito combater qualquer forma de discriminação, inclusive discriminação por orientação sexual.

\subsection{Modelos de combate à discriminação por orientação sexual: ação afirmativa}

Segundo José Claudio Monteiro de Brito Filho, o combate às práticas discriminatórias pode ocorrer de diversas formas, quer pela adoção de normas que proíbam e reprimam a discriminação, quer pela adoção de medidas que garantam a ascensão de integrantes de determinados grupos, que são denominadas ações afirmativas. ${ }^{22}$

Brito Filho identifica dois modelos: o repressor e a ação afirmativa. ${ }^{23}$ Denomina de modelo repressor o modelo que cuida da edição de normas que vedam as práticas impondo sanções de natureza criminal, civil e trabalhista no modelo mais antigo. ${ }^{24}$

Para o autor, esse modelo caracteriza-se por ser estático, pois, apesar de reprimir condutas discriminatórias, dificilmente possibilita, para pessoas e grupos discriminados, a inserção na sociedade, já que atua com o objetivo de preservar apenas a igualdade formal. ${ }^{25}$

Logo, cabe ao modelo da ação afirmativa criar oportunidades para que os grupos vulneráveis e seus integrantes possam sair da sua condição marginalizada e excluída na sociedade.

Note-se que ao se estabelecer uma diferenciação entre o modelo repressor e as medidas de ação afirmativa,

22 BRITO FILHO, José Cláudio Monteiro. Discriminação no trabalho. São Paulo: LTr, 2002.p.51-52.

23 BRITO FILHO, José Cláudio Monteiro. Trabalho decente: análise jurídica da exploração do trabalho - trabalho forçado e outras formas de trabalho indigno. São Paulo: LTr, 2004.p. 96.

24 Idem Ibidem, 52.

25 Idem Ibidem, 52. 
percebe-se que o ponto de diferença entre eles é a postura ativa. Tendo em vista que, na ação afirmativa, assume-se a postura de adotar medidas que visem garantir a inclusão na coletividade de pessoas e grupos discriminados, diferentemente do modelo repressor que tem por objeto tornar ilícitos atos e condutas discriminatórias. ${ }^{26}$

Joaquim B. Barbosa Gomes define a ação afirmativa ou discriminação positiva, como políticas ou mecanismos de inclusão concebidos por entidades públicas, privadas e por órgãos dotados de competência jurisdicional, com vistas à concretização de um objetivo constitucional universalmente reconhecido, qual seja o da efetiva igualdade de oportunidades inerentes a todos os seres humanos ${ }^{27}$

De acordo com Gabi Wucher, as ações afirmativas ou medidas de discriminação positiva têm por escopo “[...] assegurar a pessoas pertencentes a grupos particularmente desfavorecidos uma posição idêntica à dos outros membros da sociedade, proporcionando assim uma igualdade no exercício de direitos". ${ }^{28}$

O modelo da ação afirmativa consolidou-se na década de 1960, nos Estados Unidos, na Executive Order n. 10.965, de 6 de março de 1963, de iniciativa do Presidente Democrata John F. Kenedy, passando, a partir de então, a denominar qualquer iniciativa tendente à promoção da integração, do desenvolvimento e do bem-estar das minorias. ${ }^{29}$

No Brasil, as ações afirmativas possuem guarida na Lei maior, visto que é princípio fundamental do texto constitucional a promoção do bem geral. Pode-se dizer, portanto, que as ações afirmativas são instrumentos ou medidas para aferir eficácia ao objetivo fundamental da República Federativa do Brasil, que é o de promover a construção de uma sociedade livre, justa e solidária (art. $\left.3^{\circ}, \mathrm{I}, \mathrm{CF} / 88\right)$, sem preconceitos de origem, raça, sexo, cor, idade ou quaisquer outras formas de discriminação (art. $3^{\circ}$, I e IV CF/88).

No entanto, é clarividente a dissintonia entre o texto constitucional e a realidade nacional. O Brasil se encon-

26 BRITO FILHO, José Cláudio Monteiro. Discriminação no trabalho. São Paulo: LTr, 2002. p. 97.

27 GOMES, Joaquim B. Barbosa. Ação afirmativa e o princípio constitucional da igualdade. São Paulo: Renovar, 2001.p. 41.

28 WUCHER, Gabi. Minorias: proteção internacional em prol da democracia. São Paulo: Juarez de Oliveira, 2000.p. 54.

29 CRUZ, Álvaro Ricardo de Souza. O direito à diferença: as ações afirmativas como mecanismo de inclusão social de mulheres, negros, homossexuais e pessoas portadoras de deficiência. Belo Horizonte: Del Rey, 2003.p. 185. tra longe do ideal na garantia e valorização dos grupos e pessoas vulneráveis.

Tomando por base o até aqui delineado, pode-se afirmar que as ações afirmativas são mecanismos de cunho distributivo, não devendo ser vistas como "esmolas" ou "clientelismo", mas como elemento essencial ao Estado Democrático de Direito. Ou melhor, o propósito da ação afirmativa é o de redistribuir, de forma mais justa e igualitária, os recursos existentes e os meios para sua obtenção.$^{30}$

Levando em consideração as lições de Dworkin, verifica-se que o autor se vale da igualdade para realizar a construção de seu ideário de justiça. ${ }^{31}$

Sobre as ações afirmativas, é de se extrair dos ensinamentos do autor o princípio genuíno de que ninguém deve sofrer por ser membro de um grupo considerado menos digno de respeito, tratando-se tal medida das mais eficazes para assegurar a justiça.

Logo, em uma sociedade em que não é violado o direito constitucional dos indivíduos de serem tratados como iguais, é possível vislumbrar o ideal de justiça pregado por Dworkin. ${ }^{32}$

Considera Dworkin a discriminação compensatória um grande aliado na luta para se resguardar e respeitar o direito à igualdade e realizar a justiça a todos os membros de uma comunidade, mormente aqueles vulneráveis ao preconceito e à discriminação, tais como negros, indígenas, homossexuais, mulheres, pessoas com deficiência. $^{33}$

Nestes termos, pode-se extrair dos ensinamentos de Dworkin a concepção de que a ação afirmativa pressupõe condutas positivas do Estado, que tem por escopo compensar diferenças, corrigir distorções, reduzir o preconceito, efetivar a igualdade de oportunidades e respeito àqueles indivíduos ou grupos vulneráveis.

Para Dworkin, essas medidas teriam caráter definitivo, até que a igualdade entre as pessoas e grupos vulneráveis fosse alcançada. Sendo assim, a ação afirmativa vislumbra a possibilidade de tornar a sociedade mais

30 BRITO FILHO, José Cláudio Monteiro. Trabalho decente: análise jurídica da exploração do trabalho - trabalho forçado e outras formas de trabalho indigno. São Paulo: LTr, 2004.p. 101.

31 DWORKIN, Ronald. A virtude soberana: teoria e prática da igualdade. São Paulo: Martins Fontes, 2005.

32 Idem. Ibidem. [s.p]

33 Idem. Ibidem. [s.p] 
justa, mas não possui o condão de reparar injustiças historicamente sofridas.

Nas questões atinentes à homossexualidade, observa-se que, para que as ações afirmativas venham a ser utilizadas como critério para se alcançar a igualdade, é mister que elas tenham como ponto de partida políticas de conscientização e de educação acerca da orientação sexual, de modo a demonstrar que a homossexualidade não se trata de uma patologia e nem de uma opção consciente, mas de um jeito de ser, o que provavelmente reduziria o sentimento preconceituoso e arraigado da mentalidade popular.

A partir dessa conscientização, caminhar-se-ia para um segundo momento, que seria o de criar medidas efetivas objetivando a inserção social dos homossexuais, garantindo-lhes direitos e oportunidades - inclusive no mercado de trabalho - uma vez que a simples inserção formal nos textos constitucionais da proibição de condutas discriminatórias e do princípio da igualdade, não basta para que homossexuais sejam tratados com o mesmo respeito e consideração que os heterossexuais.

Ao tratar do assunto, Vera Lúcia Carlos afirma que, a partir da implementação no Brasil do Programa Nacional de Direitos Humanos, deu-se início a uma ampla discussão sobre a oportunidade de se estabelecer ações afirmativas ou políticas antidiscriminatórias em favor de grupos vulneráveis como, negros, idosos, portadores de deficiência e de HIV, homossexuais. ${ }^{34}$

No que concerne às políticas de ação afirmativa em matéria de orientação sexual, ainda que sejam escassas, o governo nacional vem avançando nesse aspecto.

Um desses avanços é o Programa de Cooperação Técnica do Ministério do Trabalho e Emprego para implementação da Convenção da no 111 OIT. Esse programa teve início em 1995 e trouxe avanços importantes. Atualmente, diversas Delegacias Regionais do Trabalho já dispõem de um núcleo específico de Promoção da Igualdade de Oportunidades e Combate à Discriminação.

Em se tratando especificamente de orientação sexual, no ano de 2004, foi desenvolvido o "Programa Brasil Sem Homofobia" que é o Programa de Combate à Violência e à Discriminação contra GLTB e de Promoção da Cidadania Homossexual. ${ }^{35}$

34 CARLOS, Vera Lúcia. Discriminação nas relações de trabalho. São Paulo: Método, 2004.p.33-34.

35 CONSELHO Nacional de Combate à Discriminação. Brasil sem homofobia: programa de combate à violência e à discrimi-
O Programa Brasil Sem Homofobia foi lançado a partir de uma série de discussões entre o Governo Federal e a sociedade civil organizada, com o intuito de promover a cidadania e os direitos humanos de lésbicas, gays, bissexuais, travestis e transexuais (LGBT), ${ }^{36}$ por meio da equiparação de direitos e do combate à violência e à discriminação homofóbicas e transfóbicas.

Esse Programa tem como princípios: a inclusão da perspectiva da não discriminação por orientação sexual; a promoção dos direitos humanos de lésbicas, gays, bissexuais, travestis e transexuais nas políticas públicas e estratégias governamentais; a produção de conhecimento para subsidiar a elaboração e a introdução de políticas públicas voltadas para o combate à violência e à discriminação por orientação sexual; a reafirmação de que a defesa, a garantia e a promoção dos direitos humanos incluem o combate a todas as formas de discriminação e de violência e que, portanto, o combate à homofobia e a promoção dos direitos humanos de homossexuais são um compromisso do Estado e de a toda sociedade brasileira. ${ }^{37}$ O Programa também é constituído de diferentes ações voltadas para:

a) apoio a projetos de fortalecimento de instituições públicas e não governamentais que atuam na promoção da cidadania LGBT e/ou no combate à homofobia;

b) capacitação em Direitos Humanos para profissionais e representantes do movimento LGBT que atuam na defesa de direitos humanos;

c) disseminação de informações sobre direitos, de promoção da autoestima LGBT; incentivo à denúncia de violações dos direitos humanos da população LGTB.

d) capacitação e disseminação de informação a gestores das diversas esferas governamentais na temática de direitos humanos da população LGBT.

e) atuar na troca de experiências de sucesso em matéria de políticas públicas em vários países do mundo, com foco nas relações do Mercosul.

O Programa Brasil Sem Homofobia busca o reconhecimento e a reparação da cidadania da população de lésbicas, gays, bissexuais, travestis e transexuais, que,

nação contra GLTB e promoção da cidadania homossexual. Brasília: Ministério da Saúde, 2004.

36 O termo atual oficialmente usado para a diversidade no Brasil é LGBT (lésbicas, gays, bissexuais, travestis, transexuais e trangêneros). A alteração do termo GLBT em favor de LGBT foi aprovada na $1^{a}$ Conferência Nacional GLBT realizada em Brasília no período de 5 e 8 de junho de 2008.A mudança de nomenclatura foi realizada a fim de valorizar as lésbicas no contexto da diversidade sexual e também de aproximar o termo brasileiro com o termo predominante em várias outras culturas.

37 Idem. Ibidem. p. 11-12 
inegavelmente, representam uma parcela relevante da sociedade brasileira e sofrem com o preconceito e com a discriminação por orientação sexual e identidade de gênero, além de outros como, raça, etnia, gênero, idade, deficiências, credo religioso ou opinião política.

Relativamente ao tema central deste artigo, o Programa "Brasil Sem Homofobia" visa garantir, por intermédio de uma política de acesso e de promoção da não discriminação por orientação sexual, a inclusão de homossexuais no mercado de trabalho.

Para encerrar, é importante destacar que tais medidas de combate à discriminação são de extrema relevância para que homossexuais possam competir no mercado de trabalho, mormente quando essas medidas referem-se à capacitação de homossexuais, pois sem medidas que promovam essa capacitação, homossexuais continuarão fadados a fazer parte do mercado informal de trabalho, a ocupar empregos que exigem menores qualificações ou mesmo acabarão por serem excluídos do mercado formal de trabalho.

Inserir homossexuais no mercado de trabalho é fundamental para garantir concretamente a dignidade desse grupo vulnerável, visto que todo cidadão, independentemente da orientação sexual, tem o direito constitucional de não sofrer desvantagem na competição por algum benefício público, simplesmente porque o grupo ao qual pertence é objeto de preconceito, discriminação ou desprezo.

\subsection{Normas de combate à discriminação por orientação sexual}

Como já mencionado, inexiste no Brasil legislação específica contra discriminação por orientação sexual, ${ }^{38}$ quer no âmbito geral, quer no âmbito do direito do trabalho.

No entanto, essa omissão legislativa não pode ser vista como uma permissão da legislação para a prática de condutas discriminatórias por tomadores de serviço, visto que tanto o direito pátrio como o internacional vedam qualquer forma de discriminação infundada no meio ambiente de trabalho.

A proibição à discriminação por orientação sexual no mercado de trabalho é prevista implicitamente na

38 Ressalta-se que neste ponto a análise da legislação interna será feita a partir do texto constitucional e leis federais, tendo em vista que em algumas legislações municipais e estaduais, tal como a Constituição do Estado do Pará (EC 20/2003), já preveem regras específicas em relação à discriminação por orientação sexual.
Carta Magna Nacional, tendo em vista que a ordem constitucional brasileira elege a dignidade da pessoa humana e o valor social do trabalho entre os fundamentos da República Federativa do Brasil (art. 1º, III e IV).

Além disso, a Constituição impõe como objetivo fundamental da República a promoção do bem de todos, sem preconceitos de origem, raça, sexo, cor, idade e quaisquer outras formas de discriminação $\left(\operatorname{art.} 3^{\circ}, \mathrm{IV}\right)$.

Essa disposição, por si só, pode ser tida como pressuposto constitucional pelo qual o Estado proíbe qualquer ato tendente a permitir qualquer forma de discriminação.

Não só isso. A determinação prevista no art. $3^{\circ}$, IV do texto constitucional impõe ao Estado que ele reúna esforços na busca de uma sociedade mais igualitária, com a eliminação de todas as formas de desigualdade. ${ }^{39}$

Pontua-se que essa repressão contra a prática de atos discriminatórios pelo Poder Constituinte Originário também é clarividente no texto do art. $5^{\circ}$, que versa sobre os direitos e garantias fundamentais e que declara a igualdade de todos perante a lei, sem distinção de qualquer natureza.

Em matéria trabalhista, o texto constitucional do art. $7^{\circ}$, incisos XXX, XXXI e XXXII, é taxativo no sentido de proibir qualquer tipo de conduta discriminatória e que importe em distinção de qualquer natureza.

Observe-se que não é só na Constituição Federal que a discriminação por orientação é vedada no direito nacional. A Lei 9.029, de 13 de abril de 1995, que proíbe a exigência de atestados de gravidez e esterilização, também proíbe outras práticas discriminatórias, para efeitos admissionais ou de permanência da relação jurídica de trabalho.

$\mathrm{O}$ art. $1^{\circ}$ da referida lei determina:

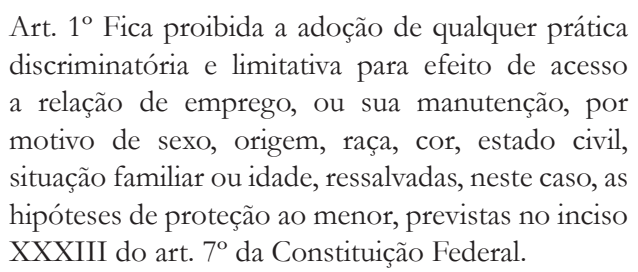

Em um primeiro momento, pode-se imaginar que o artigo deixa de fora práticas discriminatórias decorrentes da orientação sexual. Todavia, tal omissão não exclui a aplicação da Lei 9.029/95 nas hipóteses de discrimina-

39 BRITO FILHO, José Cláudio Monteiro. Discriminação no trabalho. São Paulo: LTr, 2002.p. 62. 
ção em razão da orientação sexual no mercado de trabalho, tendo em vista que a aplicação e a interpretação de tal Lei deve ser feita a partir do texto constitucional, que veda qualquer tipo de discriminação (art. $3^{\circ}$, IV). Logo, entende-se que a discriminação em razão da orientação sexual do trabalhador também se encontra albergada pelas regras contidas na Lei 9.029/95.

No que diz respeito ao direito internacional, aponta-se a Convenção 111 da Organização Internacional do Trabalho (OIT) como documento de grande relevância em matéria de discriminação. Referida Convenção foi promulgada em 1958 e com vigência a partir de 15 de junho de 1960, visando regular de forma genérica a discriminação, vedando-a em todas as suas formas e por qualquer razão.

Note-se que, em 26 de novembro de 1965, o Brasil ratificou a Convenção 111 da OIT e sua promulgação deu-se, em 1968, por meio da edição do Decreto $n^{\circ}$ 62150/68. Dispõe o art. $1^{\circ}$ da Convenção 111 da OIT:

1. Para os fins desta Convenção, o termo "discriminação" compreende:

a) toda distinção, exclusão ou preferência, com base em raça, cor, sexo, religião, opinião política, nacionalidade ou origem social, que tenha por efeito anular ou reduzir a igualdade de oportunidade ou de tratamento no emprego ou profissão;

b) qualquer outra distinção, exclusão ou preferência que tenha por efeito anular ou reduzir a igualdade de oportunidade ou tratamento no emprego ou profissão, conforme pode ser determinado pelo Paísmembro concernente, após consultar organizações representativas de empregadores e de trabalhadores, se as houver, e outros organismos adequados.

2. Qualquer distinção, exclusão ou preferência, com base em qualificações exigidas para um determinado emprego, não são consideradas como discriminação.

3. Para os fins desta Convenção, as palavras "emprego" e "profissão" compreendem o acesso à formação profissional, acesso a emprego e a profissões, e termos e condições de emprego.

A partir dessa disposição, pode-se frisar que Estado nacional, ainda que não tenha uma legislação específica para discriminação por orientação sexual, proíbe amplamente toda e qualquer forma de discriminação que impossibilite, restrinja ou inviabilize o acesso ao mercado de trabalho. Logo, com a ratificação pelo Brasil da Convenção 111 da OIT, o homossexual pode se valer dessa legislação protetiva contra condutas discriminatórias de empregados e colegas no âmbito do direito do trabalho.

Observa-se ainda que o texto da Convenção, mais precisamente no art. $5^{\circ}$, preceitua a possibilidade de cada País-membro valer-se da ação afirmativa como mecanismo para definir políticas que tenham como objetivo favorecer a determinados grupos a fim de lhes garantir inclusão social. In verbis:

1. Não são consideradas discriminatórias medidas especiais de proteção ou de assistência providas em outras convenções ou recomendações adotadas pela Conferência Internacional do Trabalho.

2. Todo País-membro pode, mediante consulta a organizações representativas de empregadores e de trabalhadores, se as houver, definir, como não discriminatórias, outras medidas especiais destinadas a atender a necessidades particulares de pessoas que, por motivo de sexo, idade, invalidez, encargos de família ou nível social ou cultural, necessitem de proteção ou assistência especial.

Ainda no plano do direito internacional, não se pode olvidar o Pacto Internacional dos Direitos Econômicos, Sociais e Culturais, adotado pela Resolução n. 2.200-A (XXI) da Assembleia Geral das Nações Unidas, em 16 de dezembro de 1966 e ratificada pelo Brasil em 24 de janeiro de $1992 .{ }^{40}$

Assim como a Convenção 111 da OIT, o Pacto Internacional dos Direitos Econômicos, Sociais e Culturais, em seu art. $2^{\circ}$, item 2 , veda qualquer tipo de prática discriminatória:

Art. $2^{\circ}-(\ldots)$

2. Os estados-partes no presente Pacto comprometem-se a garantir que os direitos nele enunciados se exercerão sem discriminação alguma por motivo de raça, cor, sexo, língua, religião, opinião política ou de qualquer outra natureza, origem nacional ou social, situação econômica, nascimento ou qualquer outra situação.

Em sendo assim, repete-se ainda que não haja uma legislação específica, tanto no plano do direito interno quanto no plano internacional, os homossexuais possuem acervo legislativo de que podem se valer, não só no âmbito laboral, mas também em qualquer âmbito em que venham sofrer violações de direitos em razão de qualquer prática discriminatória.

40 O Pacto Internacional dos Direitos Econômicos, Sociais e Culturais teve o objetivo de tornar juridicamente vinculantes os dispositivos da Declaração Internacional dos Direitos Humanos, determinando a responsabilização internacional dos Estados-partes pela violação dos direitos enumerados. O Pacto inclui o direito ao trabalho e à justa remuneração, o direito a formar e a associar-se a sindicatos, o direito a um nível de vida adequado, o direito à educação, o direito das crianças de não serem exploradas e o direito à participação na vida cultural da comunidade. 


\section{Considerações finais}

Após a análise desenvolvida, pretende-se apresentar alguns pontos que permitam reflexão em torno do tema discriminação a homossexuais no ambiente laboral.

Verificou-se, a partir do estudo aqui realizado, que ainda que o Estado e a sociedade brasileira tenham evoluído em matéria de combate à discriminação, com a entrada em vigor da Constituição Federal de 1988, e com ratificação da legislação internacional, muito ainda precisa ser feito no que tange à discriminação aos homossexuais.

A problemática referente à discriminação vivida por homossexuais no ambiente e mercado de trabalho confirma tal entendimento e faz reconhecer que, apesar da proteção constitucional e legal contra condutas discriminatórias, muitos tomadores de serviços não contratam homossexuais e outros acabam por se desfazer/discriminar o funcionário a partir do momento que ficam sabendo que sua orientação sexual é diferente da maioria.

No âmbito do mercado de trabalho, a discriminação é uma realidade vivida por muitos gays e lésbicas. A orientação sexual diferente da maioria não é vista com bons olhos pelas empresas. O estereótipo de doentes ou desviados ainda permanece encravado na sociedade e apenas reforça e estimula o tratamento discriminatório. A mentalidade heterossexista intrínseca que domina a sociedade parte da "normalidade" heterossexual para definir pessoas e grupos que se encontram excluídos dela, como no caso dos homossexuais.

Não há justificativa suficiente para aceitar que, em pleno século XXI, o ser humano sofra discriminação em razão de suas diferenças. Com efeito, as identidades pessoais devem ser respeitadas. Às pessoas devem ser atribuídos os valores e consideradas as diversidades componentes da natureza humana.

Indubitavelmente, o reconhecimento da pluralidade inerente à condição humana é pressuposto para o respeito e proteção a projetos de vida distintos daqueles tidos como padrão pela maioria da sociedade.

É certo que a definição histórica de tratar igualmente os iguais e desigualmente os desiguais na medida das suas desigualdades, deve ser entendida como uma maneira de promover a igualdade daquelas pessoas e grupos vulneráveis em razão do preconceito encravado na cultura dominante de uma sociedade.
Para isso, entende-se que apenas o uso de medidas repressivas contra atos discriminatórios revela-se insuficiente para mudar o quadro de exclusão a que estão sujeitos os homossexuais.

Considera-se a ação afirmativa a forma jurídica que deve ser utilizada para se superar a exclusão e a diminuição de grupos discriminados e para lhes garantir que suas características sejam preservadas por meio da sua inserção no seio social.

Ressalta-se que a ação afirmativa não tem a pretensão de eliminar as diferenças, mas buscar mecanismos para impulsionar a integração das pessoas e grupos discriminados.

Todavia, no campo da homossexualidade, reconhece-se a dificuldade de se implementar ações afirmativas que efetivamente garantam a igualdade a esses sujeitos discriminados.

Dentre os fatores que ajudam a dificultar as políticas afirmativas no plano da homossexualidade, podem-se enumerar dois principais, quais sejam: os parcos números de denúncias em torno da discriminação e o medo do homossexual assumir claramente diante de todos os segmentos da sociedade sua verdadeira orientação sexual.

As ações afirmativas são tanto mais efetivas, quanto mais expostos estiverem as violações aos direitos do grupo defendido; quanto mais evidente for a posição de não dominância que se ocupa no Estado em que se vive. Foi o que ocorreu com mulheres e negros.

Para surtirem efeitos nas questões ligadas à homossexualidade, em um primeiro momento, as ações afirmativas deveriam estar voltadas a uma política de educação e conscientização que visem à produção de conhecimento sobre orientação sexual como forma de extinguir, ou minimamente reduzir a barreira de preconceito contra homossexuais na mentalidade popular.

Tal política de caráter informativo serviria de base, para que, num segundo momento, fossem criadas medidas efetivas para a inserção e a integração social de homossexuais que, ainda hoje, encontram-se numa situação de exclusão e marginalidade no que diz respeito a uma série de direitos e de oportunidades garantidas apenas aos heterossexuais ou aqueles homossexuais que escondem sua verdadeira orientação sexual, por medo de sofrer discriminação da sociedade. 
Sem sombra de dúvidas, vencer a barreira do preconceito em torno do tema da homossexualidade não é uma tarefa fácil. Vencer o preconceito é uma luta árdua. ${ }^{41}$

Mas nem tudo está perdido. Homossexuais possuem a seu favor a Carta Magna Nacional, a Lei 9029/95 e os tratados e convenções de que o Brasil faz parte.

É dever do Estado Democrático de Direito assegurar o respeito à dignidade da pessoa humana, dogma que se assenta nos princípios da liberdade e da igualdade.

A proibição de discriminação em virtude de orientação sexual, engendrada pelo princípio isonômico, ordena que o preconceito, desrespeito e intolerância não prevaleçam sobre o direito fundamental de igualdade, alicerce indispensável para o convívio social que respeita a dignidade de cada ser humano. ${ }^{42}$

Além disso, como diz José Claudio Brito Filho, tem-se hoje entidades estatais como, o Ministério Público, a Justiça do Trabalho e o Ministério do Trabalho e do Emprego, todas engajadas na busca das melhorias das condições de trabalho. ${ }^{43}$

Tem-se, ainda, além da sociedade civil organizada, o movimento LGBT muito mais atuante na defesa dos direitos homossexuais, o que já contribui para minorar a questão da discriminação por orientação sexual.

Mas não é o bastante. É imprescindível que o Estado mediante uma ação informativa desmistifique estereótipos negativos em relação aos homossexuais.

É necessário que o Estado e a sociedade conscientizem-se de que a problemática da discriminação por orientação sexual urge políticas públicas que garantam ao homossexual além do respeito e da inserção na sociedade, uma vida digna e livre do medo de expor a todos sua identidade sexual.

Por derradeiro, espera-se ter contribuído com a abordagem do tema para o avanço das discussões envolvendo as discriminações motivadas pela orientação sexual.

41 SPENGLER, Fabiana Marion. União Homoafetiva: o fim do preconceito. Santa Cruz do Sul: EDUNISC. 2003.p. 214.

42 RIOS, Roger Raupp. O princípio da igualdade e a discriminação por orientação sexual: a homossexualidade no Direito brasileiro e norte - americano. São Paulo: RT, 2002.p.178.

43 BRITO FILHO, José Cláudio Monteiro. Trabalho decente: análise jurídica da exploração do trabalho: trabalho forçado e outras formas de trabalho indigno. São Paulo: LTr, 2004.p.126.
E mais, espera-se que este trabalho sirva com um impulso para que outros estudiosos desbravem a discriminação sofrida pelos homossexuais, pois se julga que esse problema precisa ser mais enfrentado e discutido no meio acadêmico.

\section{REFERÊNCIAS}

ABLGT/Projeto Aliadas. Entenda a lei. Disponível em: $\quad<$ http://www.naohomofobia.com.br/lei/index. php>. Acesso: 10 mar. 2009.

AMARAL, Sylvia Maria Mendonça do. Caso Richarlyson e a homofobia. Revista Jurista, João Pessoa, a. III, n. 92, 19/09/2006. Disponível em: <http://www.juristas. com.br $/$ mod_revistas.asp?ic $=2972>$. Acesso: 27 ago. 2007.

ANAMATRA. Os iguais de forma diferente: quando a discriminação no trabalho atinge os homossexuais. Disponível em: <http://anamatra.org.br/publ/periodicos/rev_anamatra/rev_template_int.cfm?cod_ mat $=230>$. Acesso: 17 jun. 2007.

ANJOS, Gabriele dos. Identidade sexual e identidade de gênero: subversões e permanências. Sociologias, Porto Alegre, ano 2, no 4, jul/dez 2000, p.274-305.

ASSIS, Reinaldo Mendes de. União entre homossexuais: aspectos gerais e patrimoniais. Jus Navigandi, Teresina, a. 6, n. 52, nov. 2001. Disponível em: <http://jus2. uol.com.br/doutrina $/$ texto.asp?id=2432>. Acesso: 08 set. 2005 .

BLÁBLÁBLÁ, Jornal. O mercado de trabalho. Disponível em: $\quad<$ http://jornalblablabla.blogspot.com/2007/05/omercado-de-trabalho.html>. Acesso: 10 jun. 2007.

BLUMENFELD, Warren J. Blumenfeld. Definições para trabalho. Disponível em: <http://homofobia. com.sapo.pt/trabalho.html>. Acesso em: 13 out. 2005.

BORBOREMA NETO, Ruy Telles. Sexualidade e gênero e direitos humanos: um estudo de caso Eulina. Universidade Federal do Pará, 2007.

BRANDÃO, Débora Vanessa Caús. Parcerias homossexuais: aspectos jurídicos. São Paulo: RT, 2002.

Brasil, gênero e raça. Todos unidos pela igualdade de oportunidade: teoria e prática. Brasília: Ministério do Trabalho, 1997. 
BRITO FILHO, José Claudio Monteiro. Direitos humanos, cidadania, trabalho. Belém, 2004.

. Discriminação no trabalho. São Pau-

lo: LTr, 2002.

Trabalho decente: análise jurídica da

exploração do trabalho - trabalho forçado e outras formas de trabalho indigno. São Paulo: LTr, 2004.

CARLOS, Vera Lúcia. Discriminação nas relações de trabalho. São Paulo: Método, 2004.

CARTLEDGE, Paul. História ilustrada da Grécia antiga. Rio de Janeiro: Ediouro, 2002.

CAMPBELL, Ullisses. Deputados querem que SUS pague sessão de análise para quem quer deixar de ser gay. Disponível em: <http://www.abraceh.org.br/ v2/index/index.php>. Acesso: 05 maio 2009.

CARRARA, Sérgio. Educação, diferença, diversidade e desigualdade. Disponível em: < http://www. clam.org.br/pdf/scarrara.pdf>. Acesso: 24 fev. 2010.

- Só os viris e discretos serão amados?. Disponível em: <http://www.clam. org.br/publique/cgi/cgilua.exe/sys / start. htm?infoid=330\&sid=89\&tpl=view_BR_0125> . Acesso: 24 fev. 2010.

CHIARINI JÚNIOR, Enéas Castilho. A Igreja Católica e os homossexuais: a gota d'água. Revista Jurídica del Peru, no 49, pg. 249 - 270, Lima (Peru): Editora Normas Legales, agosto de 2003.

Homoafetividade e direito: o oposto do que eu disse antes. Jus Navigandi, Teresina, a. 9, n. 625, 25 mar. 2005. Disponível em: <http://jus2.uol. com.br/doutrina $/$ texto.asp?id $=6500>$. Acesso em: 13 set. 2005

União homoafetiva sob o enfoque dos direitos humanos. Disponível: <http//www1. jus.com.br/doutrina/texto.asp?id=4902>. Acesso: 15 fev. 2005.

COELHO, Edson. Ele não usa sapatilhas, mas chuteiras. Jornal O Liberal-Belém, 26.08.2007a.

. Telma, eu não sou gay. Jornal O Liberal-Belém, 26.08.2007b.

COMPARATO, Fábio Konder. Fundamentos dos direitos humanos. São Paulo: Editora LTr.

CONSELHO Nacional de Combate à Discriminação.
Brasil sem homofobia: programa de combate à violência e à discriminação contra GLTB e promoção da cidadania homossexual. Brasília: Ministério da Saúde, 2004.

CORREIA, Jadson Dias. União civil entre pessoas do mesmo sexo (Projeto de Lei 1151/95). Jus Navigandi, Teresina, a. 1, n. 10, abr. 1997. Disponível em: <http:/ / jus2.uol.com.br/doutrina/texto.asp?id=554>. Acesso: 08 set. 2005.

CRUZ, Álvaro Ricardo de Souza. O direito à diferença: as ações afirmativas como mecanismo de inclusão social de mulheres, negros, homossexuais e pessoas portadoras de deficiência. Belo Horizonte: Del Rey, 2003.

DEL PRIORI, Mary. História do amor no Brasil. São Paulo: Contexto, 2006.

DIAS, Maria Berenice. União homossexual: o preconceito e a justiça. 2. ed.Porto Alegre: Livraria do Advogado. 2001.

Homoafetividade: o que diz a justiça!.

Porto Alegre Livraria do Advogado. 2003.

Amor não tem sexo. Disponível em: $<$ http://www.ambito-juridico.com.br/aj/dcivil0045. htm>. Acesso: 21 out. 2005.

Uma questão de justiça. Disponível em: <http://www.mariaberenice.com.br/site/>. Acesso: 05 ago. 2007.

Preconceito: crime contra a cidadania. Disponível em: $<$ http://www.mariaberenice.com.br/ site/>. Acesso: 05 ago. 2007.

DWORKIN, Ronald. Levando os direitos a sério. São Paulo: Martins Fontes, 2002.

A virtude soberana: a teoria e prática da igualdade. São Paulo: Martins Fontes, 2005.

FACCHINI, Regina. "Sopa de Letrinhas"? Movimento homossexual e produção de identidades coletivas nos anos 90: um estudo a partir da cidade de São Paulo. Dissertação (Mestrado em Antropologia) -Departamento de Antropologia do IFCH,UNICAMP, Campinas, SP, 2002.

FALCÃO, Luciene Campos. Adoção de crianças por homossexuais: crenças e formas de preconceito. Universidade Católica de Goiás, 2004. 
FERREIRA, Aurélio Buarque de Holanda. Minidicionário da língua portuguesa. 3. ed. Rio de Janeiro: Nova Fronteira, 1993.

FERREIRA, Cilene Marques. Os estigmas na vida cotidiana dos portadores de necessidades especiais. Unama, 2006.

FERNANDES, Taísa Ribeiro. Uniões homossexuais: efeitos jurídicos. São Paulo: Editora Método. 2004.

FACHIN, Rosana Amara Girardi. Em busca da família do novo milênio. Rio de Janeiro: Renovar, 2001.

FIUZA, Ricardo. O novo Código Civil e as propostas de aperfeiçoamento. São Paulo: Saraiva.

GLOBO, Rede.Professoras discriminadas.Disponível em:<http:/ / fantastico.globo.com/Jornalismo/Fantasti co/0,AA1662347-4005-755999-0-18112007,00.html>. Acesso: 20 nov. 2007.

GOFFMAN, Erving. Estigma: notas sobre a manipulação da identidade deteriorada. 4.ed.Rio de Janeiro: Guanabara, 1988.

GUGEL, Maria Aparecida. Discriminação do homossexual nas relações de trabalho. Disponível em: <http://www.pgt.mpt.gov.br/pgtgc/publicacao/engine.wsp?tmp.area $=219 \&$ tmp.texto $=1080>$. Acesso: 17 dez. 2008.

KOTLINSKI, Kelly; CEZÁRIO, Joelma Cezário; NAVARRO, Melissa. Legislação e jurisprudência LGBT'TT: lésbicas - gays - bissexuais - travestis - transexuais - transgêneros. Anis: Instituto de Bioética, Direitos Humanos e Gênero; Associação Lésbica Feminista de Brasília Coturno de Vênus. Brasília: LetrasLivres, 2007.

MARTINS, Sérgio Pinto. Direito do trabalho. São Paulo: Atlas, 2001.

MAURER, Béatrice. Notas sobre o respeito da dignidade da pessoa humana ou pequena fuga incompleta em torno de um tema central. Porto Alegre: Livraria do Advogado, 2005.

MAZZAROLO, Isidoro. Homossexualidade e sexualidade na Bíblia: alguns tópicos pra o debate. Disponível em: <http://www.itf.org.br/index.php?p $\mathrm{g}=$ conteudo $\&$ revistaid $=4 \&$ fasciculoid $=18 \&$ sumario $\mathrm{id}=132>$. Acesso: 14 out. 2005.

MELLO, Luiz. Outras famílias: a construção social da conjugalidade homossexual no Brasil. Cadernos Pagu $\mathbf{n}^{\mathbf{o}} 24$ Campinas Jan./June 2005. Disponível em: <http://www.scielo.br/scielo.php?script=sci_arttext \&pid=S0104-83332005000100010 >. Acesso: 20 fev. 2010.

MORAES, Alexandre de. Direito constitucional. São Paulo: Atlas, 2002.

NUSSBAUMER,Gisele Marchiori. Cultura e identidade gay: a diferença do múltiplo. INTERCOM - Sociedade Brasileira de Estudos Interdisciplinares da Comunicação. XXIV Congresso Brasileiro de Ciências da Comunicação - Campo Grande - MS.

PAMPLONA FILHO, Rodolfo. Orientação sexual e discriminação no emprego. Jus Navigandi, Teresina, ano 5, n. 51, out. 2001. Disponível em: <http://jus2. uol.com.br/doutrina/texto.asp?id=2049>. Acesso em: 08 ago. 2008.

PATEMAN, Carole. O contrato sexual. São Paulo: Paz e Terra, 1993.

PIOVESAN, Flávia \& RIOS, Roger Raupp. A Discriminação por gênero e por orientação sexual. Disponível em: <http://www.cjf.gov.br/revista/seriecadernos/vol24/artigo05.pdf>. Acesso: 04 ago. 2007.

PRADO, Marco Aurélio Máximo \& VIANA, Frederico Machado. Preconceito contra a homossexualidade: a hierarquia da invisibilidade. São Paulo: Cortez, 2008.

RABENHORST, Eduardo Ramalho. Dignidade humana e moralidade democrática. Brasília: Brasília Jurídica, 2001.

RIOS, Roger Raupp. O princípio da igualdade e a discriminação por orientação sexual: a homossexualidade no Direito brasileiro e norte- americano. São Paulo: RT, 2002.

Os iguais de forma diferente: quando a discriminação no trabalho atinge os homossexuais. Disponível em: <http://anamatra.org. $\mathrm{br} / \mathrm{publ} / \mathrm{periodicos} / \mathrm{rev}$ _anamatra/rev_template_int. cfm?cod_mat=230> Acesso: 17 jun. 2007.

A homossexualidade e a discriminação por orientação sexual no direito brasileiro. Disponível em: <http://www.senado.gov.br/web/cegraf/ril/Pdf/pdf_149/r149-23.pdf>. Acesso: 04 ago. 2007.

SARLET, Ingo Wolfgang. Dignidade da pessoa humana e direitos fundamentais na Constituição Federal de 1988. Porto Alegre: Livraria do Advogado, 2006. 
SILVA, Adriana Nunan do Nascimento. Homossexualidade e discriminação: o preconceito sexual internalizado. Pontifícia Universidade Católica do Rio de Janeiro, Rio de Janeiro, 2007.

SILVA, José Afonso da. Curso de direito constitucional positivo. São Paulo: Malheiros.

SPENGLER, Fabiana Marion. União homoafetiva: o fim do preconceito. Santa Cruz do Sul: Editora EDUNISC. 2003.
Um Outro Olhar, Rede. Professoras discriminadas em

Campo Grande. Disponível em: $<$ http://www.umoutroolhar.com.br/em_movimento.htm\#Professoras_discriminadas_em_Campo_Grande>. Acesso: 25 nov. 2007.

VELOSO, Zeno. Um amor ainda à margem da lei. Jornal O Liberal - Belém, 30.03.2003.

VERDON, Jean. Ser homossexual não é tabu. Revista História Viva, São Paulo-SP, ano I, n 5, p.44, março 2004. 
Para publicar na Revista de Direito Internacional, acesse o endereço eletrônico www.rdi.uniceub.br ou www.brazilianjournal.org.

Observe as normas de publicação, para facilitar e agilizar o trabalho de edição. 